\title{
Third-line tigecycline antibiotic for Acinetobacter Baumannii in- fection in feline pyothorax
}

\author{
Zulfa IRCF $^{1}$, Siti Zaenab ${ }^{1}$, Deni Noviana ${ }^{1,2,3}$, Sukmasari Arifah $^{1,} \ddagger$ \\ ${ }^{1}$ My Vets Animal Clinic Jakarta \\ ${ }^{2}$ Cardiology Center Service, Veterinary Teaching Hospital, Faculty of Veterinary Medicine, IPB University \\ ${ }^{3}$ Department of Clinic, Reproduction, and Pathology, Faculty of Veterinary Medicine, IPB University
}

\begin{abstract}
A one-year-old domestic shorthair male cat was presented to the clinic with severe dyspnoea. The cat has a history of recurrence bronchial disease with coughing as a major clinical sign. The cat never be hospitalized and clinical symptoms will disappear after antibiotic and glucocorticoid administration within a few days. On physical examination, the cat was dehydrated and apathetic. Dullness thoracic percussion was detected. Other organs out of thorax did not show abnormality. Thoracic radiography revealed pleural effusion. Purulent fluid was obtained by thoraco centesis and cytologic examination result was septic exudates. Hematological result was marked leukocytosis (59.69x10^9 g/l). Enrofloxacin was given as empirical antibiotic until culture results released. On the $7^{\text {th }}$ day of Enrofloxacin administration, there was only a slight decrease in leucocyte count. Bacterial culture results was Acinetobacter baumannii (A. baumanii) that are sensitive to Meropenem and Tigecycline from antibiotic resistance test. Previous antibiotic was stopped and replaced with intravenous Meropenem. Moderate decrease of leucocytes count $\left(28.03 \times 10^{\wedge} 9 \mathrm{~g} / \mathrm{l}\right)$ obtained on day $18^{\text {th }}$ of Meropenem treatment and patient shows good clinical sign progress. Meropenem resistancy were considered when leucocytes count increased on the $20^{\text {th }}$ day as A. baumanii is extremely multi-resistant organism. Third-line Tigecycline was administered as the last choice use of antibiotic and stop after leucocyte returned to normal on the $7^{\text {th }}$ day of the treatment. The cat is fully recovered from Acinetobacter Baumannii infection pyothorax treated using third-line Tigecycline antibiotics.
\end{abstract}

Keywords:

feline pyothorax, Acinetobacter baumannii, tigecycline, multi resistant organism, third-line antibiotic

\section{- CASE}

A 1-year-old, male DSH cat was presented to the clinic due to severe dyspnoe and anorexia. The cat has a history of a few months recurrence coughing and diagnosed as a mild tracheobronchitis. Clinical signs dissapear with first line antibiotic and low dose glucocorticoid. During physical examination the cat was dehydration, apatethic and dullness thoracic percussion was detected.

\section{- RESULTS}

Haematological results show dehydration polycythaemia and marked leucocytosis $\left(59.69 \times 10^{\wedge} 9 \mathrm{~g} / 1\right)$ indicating severe bacterial infection (Fig. 1). Thoracic radiograph revealed pleural efusion (Fig. 2) and purulent exudates was removed from pleura through thoraco centesis procedure. The cat receive enrofloxacin $5 \mathrm{mg} / \mathrm{kg}$ bb sid until culture result released.

On $7^{\text {th }}$ days enrofloxacin, cat's condition worsen and the WBCs count does not show significance change (Fig. 1). The culture result revealed Acinetobacter baumannii as a pathogen cause. Antibiotic resistancy results only Meropenem $(\mathrm{MIC} \leq 0.25)$ and Tigecycline $(\mathrm{MIC} \leq 0.50)$ are susceptible antibiotic. Meropenem was choosen for this case. Consideration is due to the lowest MIC and to preserved the use of Tigecycline as a last choice.

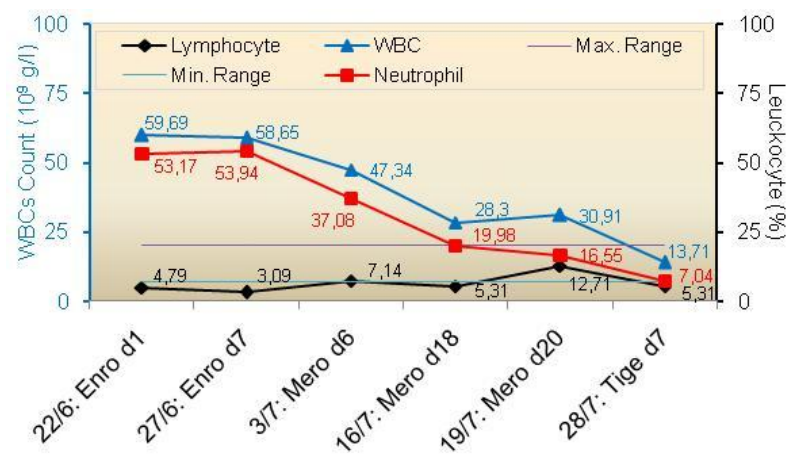

Figure 1. WBCs progression during antibiotic treatment.

On $18^{\text {th }}$ days of Meropenem, WBCs count decreas a half from initial treatment (Fig. 1), the cat also seems fully recoverd. Haematological evaluation was expected to be normal at the end of treatment period. However, WBCs has mild increasing at $20^{\text {th }}$ days of therapy. The cat shows no

Received: 01-01-2020 | Revised: 27-01-2020 | Accepted: 02-02-2020

(c) 2020 CC-BY-SA. This is an Open Access article that is distributed under the terms of Creative Commons Attribution ShareAlike 4.0 International License (https://creativecommons.org/licenses/by-sa/4.0/). 
abnormality but thoracic radiographed revealed effusion still remain on cranial pleural cavities (Fig. 2).
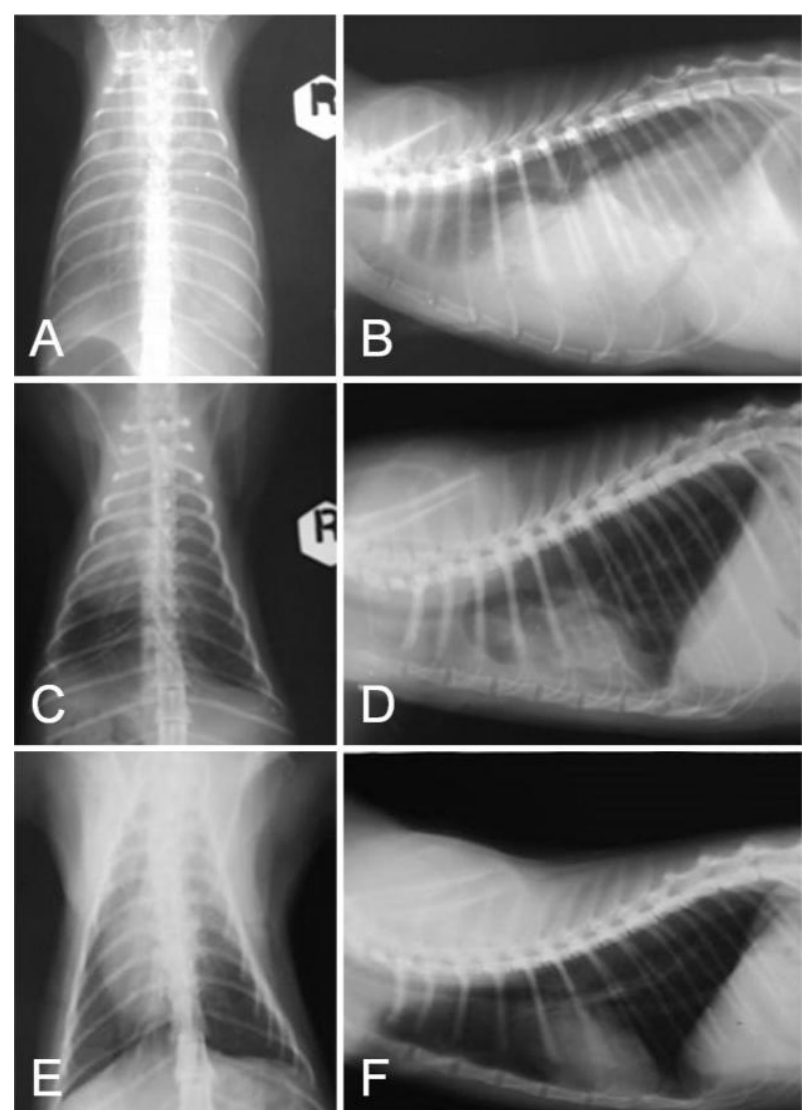

Figure 2. Thoracalis radiographic in dorso-ventral view (A,C,E) and latero-lateral requmbency view $(\mathrm{B}, \mathrm{D}, \mathrm{F})$ of the patient pre treatment $(\mathrm{A}, \mathrm{B}) ; 18^{\text {th }}$ days of Meropenem treatment $(\mathrm{C}, \mathrm{D})$; and $7^{\text {th }}$ days of Tigecycline treatment (E,F).

The haematological changes and radiograph results is the main consideration of a high risk of A. baumannii developing resistancy. Antibiotic then switched to Tigecycline with human paediatric dose at $2 \mathrm{mg} / \mathrm{kg} \mathrm{BW}$ in $100 \mathrm{ml} \mathrm{NaCl} 0.9 \%$ as a CRI 30 min every 12 hours on first day of initial treatment. The dosage divide into $1 \mathrm{mg} / \mathrm{kg} \mathrm{BW}$ every 12 hours CRI $30 \mathrm{~min}$ for the next $6^{\text {th }}$ days. WBCs count comes back to normal range in $7^{\text {th }}$ days of Tigecycline treatment (Fig. 1), and thorax radiograph significantly clear (Fig. 2). The cat fully recover and owner claimed no reccurence clinical signs again.

\section{- DISCUSSION}

A.baumannii is Gram-negative aerobic coccobacillus and was part of ESKAPE pathogen (Enterococcus faecium, Staphylococcus aureus, Klebsiella pneumoniae, Acinetobacter baumannii, Pseudomonas aeruginosa and Enterobacter spp). Its a highly multi-, extended- or pandrug resistant strains. A. baumannii known as a widespread nosocomial pathogen in human hospital (Howard et al. 2012). Third-line antibiotics is use for treatment of multidrug-resistant organisms. These antibiotics must only be used when there is culture evidence of sensitivity, no first- or second-line antibiotics are effective, and topical antimicrobial therapy is not feasible or effective (Authier et al. 2006). Tigecycline is the first drug in the glycylcycline class of tetracycline antibiotics. It has a broad spectrum of activity against many Gram positif, Gram negative and anaerobic organism. It was develop as a third line antibiotic against high resistance microbes (Greer 2006).

The initial cause of the cat infected with A. baumannii until pyothorax was develop remains unclear. The cat never been hospitalizedand stay as an indoor cat with no bite wound incident history as the owner claimed. The owner works as a professional medical personelat various general human hospitals. It might increase repetition exposure of A.baumannii to the cat when she comes home from working. The cat might also under immunocompromise, increasing the risk of excacerbatemild bronkhitis develop into pyothorax in few months. However these possibility and another port the entry need to be fully investigated.

\section{- CONCLUSION}

The cat is fully recovered from Acinetobacter Baumannii infection pyothorax treated using third-line Tigecycline antibiotics.

\section{- AUTHOR INFORMATION}

\section{Corresponding Author}

* ZIRCF: zulfa.koshka@gmail.com

My Vets Animal Clinic, Jalan Kalimantan Blok F2, No.32, Nusaloka, BSD, Tanggerang Selatan Banten

\section{Author Contributions}

$\$$ These authors contributed equally.

\section{- REFERENCES}

Authier S, Paquette D, Labrecque O, Messier S. 2006. Comparison Of Susceptibility to Antimicrobials of Bacterial Isolates from Companion Animals in A Veterinary Diagnostic Laboratory in Canada Between 2 Time Points 10 Years Apart. Canadian Veterinary Journal. 147: 774-778.

Greer ND. 2006. Tigecycline (Tygacil): The First In The Glycylcycline Class of Antibiotics. Proc (Bayl Univ Med Cent). 19(2):155-161.

Howard A, O'Donoghue M, Feeney A, Sleator RD. 2012. Acinetobacter Baumannii: An Emerging Opportunistic Pathogen. Virulence. 3(3):243-250. 